\title{
Solusi Persamaan Burgers Inviscid dengan Metode Pemisahan Variabel
}

\author{
Hisyam Ihsan ${ }^{1, \text { a) }}$, Syafruddin Side ${ }^{1, b)}$, dan Muhammad Iqbal ${ }^{1, c)}$ \\ ${ }^{1}$ Jurusan Matematika FMIPA Universitas Negeri Makassar \\ a) hisyamihsan@gmail.com \\ b)syafruddin@unm.ac.id \\ c)iqbaledogawa6@gmail.com
}

\begin{abstract}
Abstrak. Penelitian ini mengkaji tentang solusi persamaan Burgers Inviscid dengan metode pemisahan variabel. Tujuan dari penelitian ini adalah untuk mengetahui penyederhanaan sistem persamaan NavierStokes menjadi persamaan Burgers Inviscid, menemukan solusi persamaan Burgers Inviscid dengan metode pemisahan variabel, dan melakukan simulasi solusi persamaan dengan menggunakan software Maple18. Persamaan Burgers muncul sebagai penyederhanaan model yang rumit dari sistem persamaan Navier-Stokes. Persamaan Burgers adalah persamaan diferensial parsial hukum konservasi dan merupakan masalah hiperbolik, yaitu representasi nonlinier paling sederhana dari persamaan NavierStokes. Metode pemisahan variabel merupakan salah satu metode klasik yang efektif digunakan dalam menyelesaikan persamaan diferensial parsial dengan mengasumsikan $u(x, t)=x t$ untuk mendapatkan komponen $x$ dan t. Kemudian akan dilakukan subtitusi pada persamaan diferensial, sehingga dengan cara ini akan didapatkan solusi persamaan diferensial parsial.
\end{abstract}

Kata Kunci: Persamaan Burgers Inviscid, metode pemisahan variabel, persamaan Navier-Stokes.

Abstract. This study examines the solution of Burgers Inviscid equation with variable separation method. The purpose of this study was to find out the simplification of the Navier-Stokes equation system into the Burgers Inviscid equation, find a solution to the Burgers Inviscid equation with the variable separation method, and simulate equation solutions using Maple18 software. The Burgers equation emerged as a complicated simplification of the Navier-Stokes equation system. The Burgers equation is a partial differential equation of conservation law and is a hyperbolic problem, i.e. the simplest nonlinear representation of the Navier-Stokes equation. The variable separation method is one of the classic methods that is effectively used in solving partial differential equations assuming $u(x, t)=x t$ to obtain the $x$ and $t$ components. Then there will be substitutions to differential equations, so that in this way there will be a partial differential equation solution.

Keywords: Burgers Inviscid Equation, variable separation method, Navier-Stokes equations.

\section{LATAR BELAKANG}

Persamaan Burgers adalah persamaan diferensial parsial dalam model difusi-adveksi-tidak linear yang biasanya memiliki satu variabel dalam ruang satu dimensi. Persamaan Burgers merupakan bentuk khusus persamaan yang dapat diperoleh dari sistem persamaan Navier-Stokes. Sistem persamaan Navier-Stokes berbentuk sebagai berikut

$$
\nabla . v=0,
$$




$$
(\rho v)_{t}+\nabla \cdot(\rho v v)+\nabla p-\mu \nabla^{2} v=0
$$

dengan, $\rho$ adalah massa jenis fluida (kerapatan fluida), $\mu$ adalah viskositas fluida, $p$ adalah tekanan, dan $v$ adalah kecepatan.(Ripai dkk, 2019). Persamaan (1) menggambarkan dinamika bebas divergensi $\left(\rho_{t}=0\right)$ di mana efek gravitasi dapat diabaikan. Sehingga penyederhanaan akan dilakukan dari persamaan (2) yang dikombinasikan dengan $\nabla^{2}$. Diketahui bahwa $\nabla^{2}=\frac{\partial^{2}}{\partial x^{2}}+$ $\frac{\partial^{2}}{\partial y^{2}}+\frac{\partial^{2}}{\partial z^{2}}$ merupakan skalar sehingga dapat disubstitusi pada persamaan (2) (Landajuela, 2011). Sehingga persamaan (2) menjadi

$$
\rho \frac{\partial v_{x}}{\partial t}+\rho v_{x} \frac{\partial v_{x}}{\partial x}+\rho v_{y} \frac{\partial v_{x}}{\partial y}+\rho v_{z} \frac{\partial v_{x}}{\partial z}+\frac{\partial p}{\partial x}-\mu\left(\frac{\partial^{2} v_{x}}{\partial x^{2}}+\frac{\partial^{2} v_{x}}{\partial y^{2}}+\frac{\partial^{2} v_{x}}{\partial z^{2}}\right)=0
$$

apabila mempertimbangkan masalah satu dimensi, dimana variabel selain $x$ bernilai nol dan tekanan diabaikan $(p=0)$, akibatnya persamaan (3) menjadi

$$
\frac{\partial u}{\partial t}+u \frac{\partial u}{\partial x}=\varepsilon \frac{\partial^{2} u}{\partial x^{2}}
$$

dengan membagi persamaan (4) dengan $\rho$ dan memisalkan $\varepsilon=\frac{\mu}{\rho}$ serta $u=v_{x}$, maka diperoleh

$$
\begin{gathered}
\frac{\partial u}{\partial t}+u \frac{\partial u}{\partial x}=0 \\
u(x, 0)=f(x)
\end{gathered}
$$

persamaan (4) adalah persamaan Burgers viscid sedangkan persamaan (5) adalah persamaan Burgers inviscid dengan kondisi awal persamaan (6).

Persamaan Burgers muncul sebagai penyederhanaan model yang rumit dari sistem persamaan Navier-Stokes. Persamaan Navier-Stokes merupakan persamaan fluida yang didasarkan pada kekekalan massa (kontinuitas), kekekalan momentum, dan kekekalan energi. Persamaan NavierStokes diungkapkan dalam suku inersia, gaya, tekanan, dan viskositas (Hapsoro, 2018).

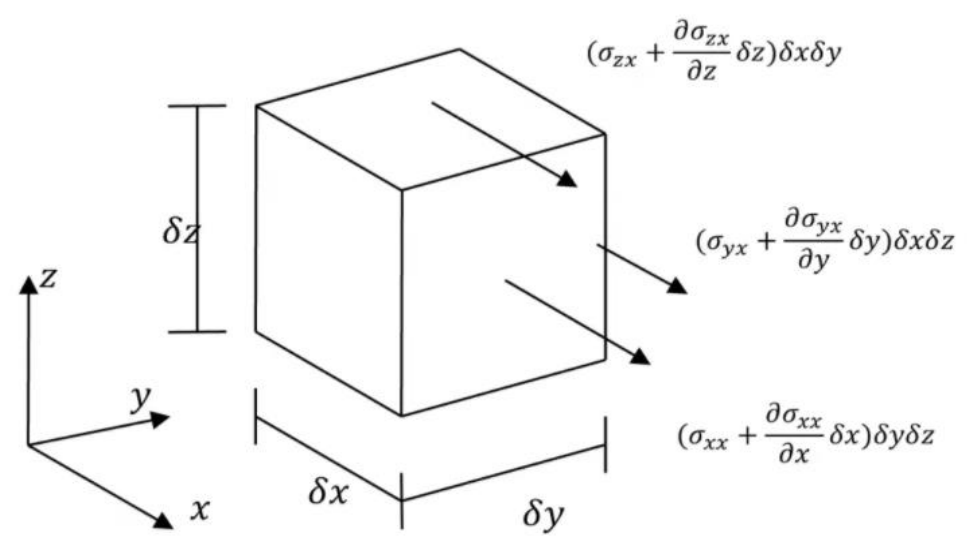

GAMBAR 1. Elemen fluida dengan volume 3 variabel

Menurut Handayani dkk (2017), Persamaan Navier-Stokes adalah bentuk diferensial dari hukum kedua Newton tentang gerakan yang ditinjau pada gambar 1 dengan massa dari elemen fluida yaitu volume $\delta x \delta y \delta z$, kemudian percepatan (a) dalam arah $x, y$, dan $z$ diperoleh melalui turunan (derivatif) dari kecepatan fluida $(v)$ dalam arah $x, y$, dan $z$ pula, serta keseimbangan gaya-gaya yang bekerja pada gambar 1 akibat tegangan normal $(\sigma)$, tegangan geser $(\tau)$, dan gaya akibat gesekan fluida dalam arah $x, y$, dan $z$.

Persamaan non linear Burgers merupakan persamaan translasi nonlinear dimana ruas kanannya memuat satu konstanta dikalikan dengan turunan kedua dari u terhadap $x$ (Khudzaifah, 2017). Untuk bidang yang diberikan $u(x, t)$ dan koefisien difusi (atau viskositas kinematik, seperti dalam konteks mekanis fluida asli) $\varepsilon$, bentuk umum persamaan Burgers (Persamaan Burgers Viscid) dalam satu dimensi ruang adalah 


$$
\frac{\partial u}{\partial t}+u \frac{\partial u}{\partial x}=\varepsilon \frac{\partial^{2} u}{\partial x^{2}}
$$

Ketika istilah difusi tidak ada Persamaan Burgers Viscid menjadi Persamaan Burgers Inviscid (Persamaan Burgers Tidak Terlihat). Persamaan Burgers Inviscid adalah kasus khusus persamaan gelombang nonlinear dimana kecepatan gelombang $v_{x}=u$, dengan $u$ adalah variabel terikat yang bergantung pada variabel bebas yaitu $x$ dan variabel waktu yaitu $t$ (Ripai dkk, 2019; Salih, 2015).

$$
\begin{gathered}
\frac{\partial u}{\partial t}+u \frac{\partial u}{\partial x}=0, \quad x \in R-\{0\}, t>0 \\
u(x, 0)=f(x)
\end{gathered}
$$

Metode pemisahan variabel merupakan salah satu teknik klasik yang efektif untuk menyelesaikan beberapa persamaan diferensial parsial. Metode pemisahan variabel yang akan digunakan pada penelitian ini terdiri dari beberapa langkah, yaitu menentukan persamaan diferensial dan kondisi awal persamaan, dalam menentukan solusi $u(x, t)$ dengan cara menentukan solusi komponen dan dapat diasumsikan menjadi $u(x, t)=X(x) T(t)=x t$. Kemudian akan dilakukan subtitusi pada persamaan diferensial, sehingga dengan cara ini akan didapatkan solusi persamaan diferensial parsial (Nagle dkk, 2012).

Penelitian tentang persamaan Burgers pada umumnya berkaitan dengan cara memperoleh solusi dari persamaan Burgers itu sendiri. Pada penelitian yang dilakukan oleh Landajuela (2011), menjelaskan secara umum model persamaan Burgers dan juga menganalisis solusi persamaan Burgers inviscid dengan metode karakteristik dan metode numerik. Kemudian, penelitian yang dilakukan oleh Mungkasi (2020), dimana penyelesaian persamaan Burgers inviscid melibatkan reaksi logistik. Sedangkan, penelitian Ahmad Ripai dkk (2019) dilatarbelakangi oleh perbedaan solusi pada persamaan Burgers, saat mekanisme penyelesaian persamaan menggunakan transformasi Hopf-Cole yang berlandaskan pada Transformasi Fourier. Persamaan dari ketiga penelitian tersebut dengan penelitian ini adalah penyelesaian persamaan Burgers inviscid. Sedangkan perbedaannya terletak pada metode yang akan digunakan penelitian ini, yaitu metode pemisahan variabel. Oleh karena itu artikel ini akan membahas tentang analisis penyelesaiaan persamaan Burgers inviscid dengan menggunakan metode pemisahan variabel.

\section{HASIL DAN SIMULASI}

Penyelesaian persamaan Burgers Inviscid dengan metode pemisahan variabel, akan dilakukan dengan langkah - langkah sebagai berikut.

1. Persamaan yang akan diselesaikan yaitu persamaan Burgers inviscid

$$
\frac{\partial u}{\partial t}+u \frac{\partial u}{\partial x}=0
$$

2. Menentukan kondisi awal dari persamaan Burgers Inviscid yaitu sebagai berikut

$$
u(x, 0)=f(x)
$$

3. Melakukan penyelesaian persamaan Burgers inviscid dengan menggunakan metode pemisahan variabel.

Asumsikan

$$
u=x t
$$

Persamaan (7) disubstitusikan pada persamaan (5), maka diperoleh

$$
\begin{gathered}
\frac{\partial}{\partial t}(x t)+(x t) \frac{\partial}{\partial x}(x t)=0 \\
\left(x t^{\prime}\right)+(x t)\left(x^{\prime} t\right)=0
\end{gathered}
$$

Selanjutnya persamaan (8) dikalikan dengan $\frac{1}{x t^{2}}$ sehingga diperoleh

$$
\left(x t^{\prime}\right) \frac{1}{x t^{2}}+(x t)\left(x^{\prime} t\right) \frac{1}{x t^{2}}=0
$$




$$
\begin{gathered}
\frac{t \prime}{t^{2}}+x^{\prime}=0 \\
\frac{t \prime}{t^{2}}=-x^{\prime}
\end{gathered}
$$

Karena ruas kanan pada persamaan (9) merupakan fungsi $x$ saja dan ruas kirinya merupakan fungsi $t$ saja, akibatnya persamaan tersebut harus sama dengan bilangan yang konstan (Side, 2014), maka diperoleh

$$
\begin{gathered}
\frac{t^{\prime}}{t^{2}}=k \\
-x^{\prime}=k
\end{gathered}
$$

4. Menentukan solusi umum persamaan Burgers inviscid.

Selanjutnya menentukan nilai $x$ dan $t$ dengan mengintegralkan kedua ruas dari persamaan (10) dan (11). Untuk persamaan (10) diperoleh

$$
\begin{gathered}
\int \frac{t^{\prime}}{t^{2}} d t=\int k d t \\
\int t^{-2} d t=\int k d t \\
-\frac{1}{t}+C_{1}=k t+C_{2} \\
-\frac{1}{t}=k t+C_{3}, C_{3}=C_{2}-C_{1} \\
1=-k t^{2}-t C_{3} \\
t C_{3}=-k t^{2}-1 \\
t=-\frac{k t^{2}+1}{C_{3}}
\end{gathered}
$$

Sedangkan untuk persamaan (11) diperoleh

$$
\begin{gathered}
\int-x d t=\int k d t \\
-x+C_{4}=k x+C_{5} \\
-x=k x+C_{6}, C_{6}=C_{5}-C_{4} \\
x+k x=-C_{6} \\
x(1+k)=-C_{6} \\
x=-\frac{C_{6}}{(1+k)}
\end{gathered}
$$

Dengan subtitusi persamaan (12) dan (13) ke persamaan (7), maka diperoleh solusi umum persamaan Burgers inviscid sebagai berikut

$$
\begin{gathered}
u(x, t)=\left(-\frac{C_{6}}{(1+k)}\right)\left(-\frac{k t^{2}+1}{C_{3}}\right) \\
u(x, t)=\frac{C_{6}\left(k t^{2}+1\right)}{C_{3}(k+1)} \\
u(x, t)=C \frac{\left(k t^{2}+1\right)}{(k+1)}, \frac{C_{6}}{C_{3}}=C
\end{gathered}
$$

5. Menentukan solusi khusus persamaan Burgers inviscid.

Untuk menentukan solusi khusus dari persamaan Burgers inviscid dilakukan dengan cara mensubtitusi kondisi batasnya yaitu persamaan (6) ke persamaan (14) sehingga diperoleh

$$
\begin{gathered}
u(x, 0)=C \frac{(k(0)+1)}{(k+1)} \\
f(x)=\frac{C}{(k+1)}
\end{gathered}
$$

Jadi solusi khusus dari persamaan Burgers inviscid adalah

$$
u(x, t)=\frac{c}{(k+1)}\left(k t^{2}+1\right)=f(x)\left(k t^{2}+1\right)
$$




\section{Simulasi}

Selanjutnya akan dijelaskan salah satu contoh simulasi pada persamaan Burgers inviscid. Diberikan persamaan Burgers inviscid sebagai berikut :

$$
\frac{\partial u}{\partial t}+u \frac{\partial u}{\partial x}=0,0 \leq x \leq 2 \pi, t>0
$$

dengan kondisi awal

$$
u(x, 0)=\sin x
$$

Masalah (16) dan (17) akan diselesaikan dengan menggunakan metode pemisahan variabel. Berdasarkan pembahasan sebelumnya, diketahui bahwa solusi persamaan Burgers inviscid dengan metode pemisahan variabel yaitu persamaan (15). Sehingga diperoleh solusi persamaan Burgers dengan kondisi awal persamaan (17) adalah

$$
u(x, t)=\sin x\left(k t^{2}+1\right)
$$

dengan menggunakan aplikasi Maple18, perhatikan grafik dari kondisi awal persamaan Burgers inviscid (17) berikut

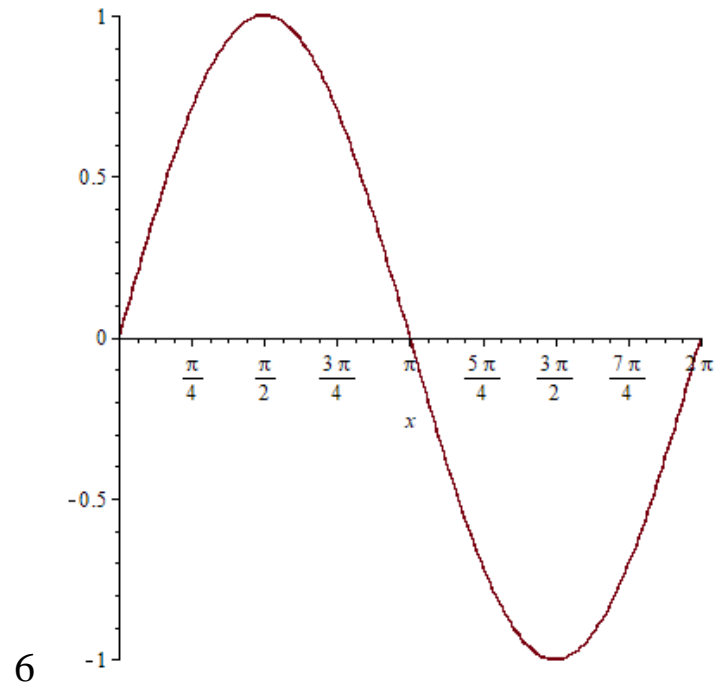

GAMBAR 2. Grafik kondisi awal $u(x, 0)=\sin x, 0 \leq x \leq 2 \pi$

Karena terdapat nilai $k$ yang merupakan suatu konstanta. Dengan menggunakan Maple18 akan diperlihatkan grafik saat $k=\{-2021,-5,-1,0,1,5,2021\}$ dengan $t=0$ sampai $t=10$.

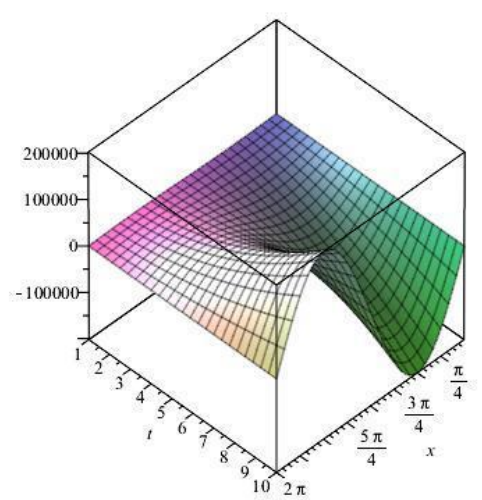

(a)

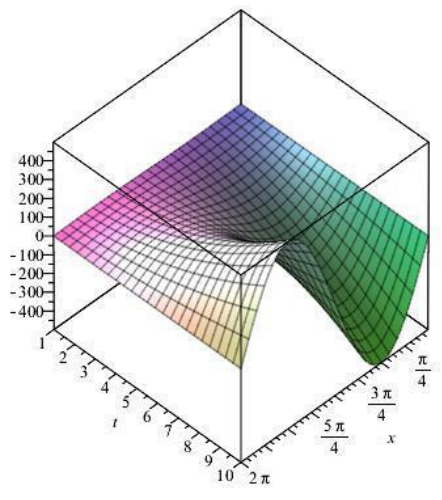

(b) 


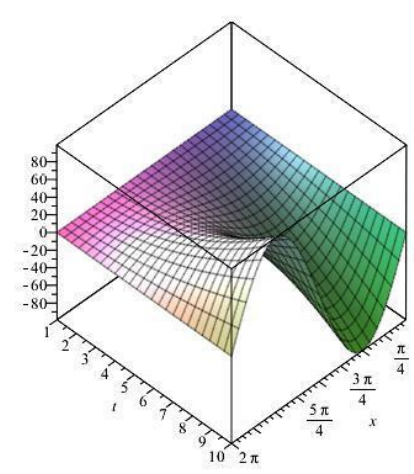

(c)

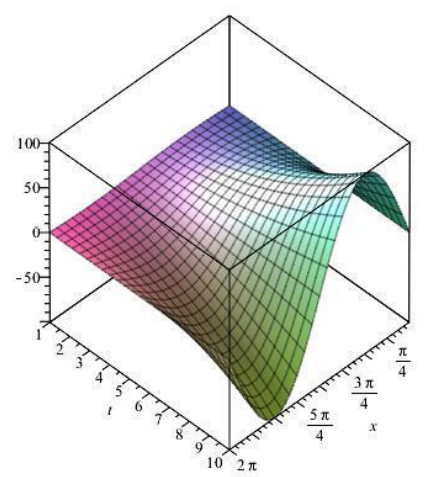

(e)

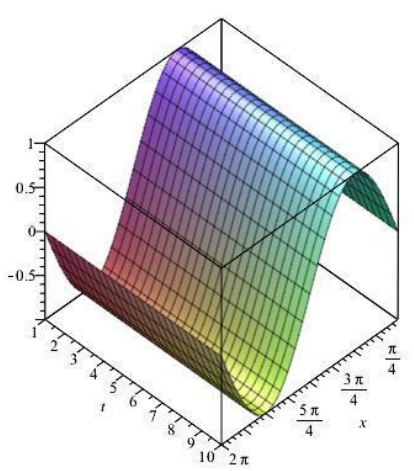

(d)

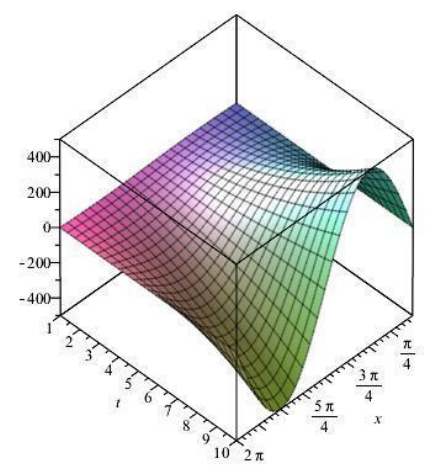

(f)

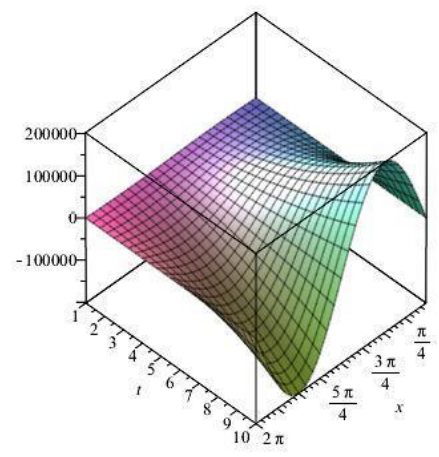

(g)

GAMBAR 3. Grafik solusi khusus persamaan saat (a) $k=-2021$, (b) $k=-5$, (c) $k=-1$, (d) $k=0$, (e) $k=1$, (f) $k=5$, dan (g) $k=-2021$

Berdasarkan dari gambar 3, diketahui bahwa solusi persamaan saat $k=-5,-1$, dan -2021 memiliki bentuk grafik yang sama namun nilai solusi $u(x, t)$ atau kecepatan gelombang $\left(v_{x}\right)$ yang berbeda begitupun juga saat $k=1,5$, dan 2021. Sedangkan, saat $k=0$ nilai solusi $u(x, t)$ sama dengan kondisi awalnya. Dari grafik tersebut juga dapat disimpulkan bahwa tidak adanya perubahan signifikan pada grafik tersebut saat menggunakan nilai $k$ yang terbesar dan terkecil, 


\section{KESIMPULAN}

Berdasarkan pembahasan sebelumnya maka dapat disimpulkan bahwa

1. Dalam menyelesaikan dan menganalisis persamaan Burgers inviscid diperoleh dengan menyederhanakan sistem persamaan Navier Stokes dengan mengkombinasikan dengan $\nabla^{2}$ dan memisalkan viskositas fluida sama dengan nol.

2. Solusi khusus dari persamaan Burgers inviscid yang diperoleh pada penelitian ini adalah

$$
u(x, t)=f(x)\left(k t^{2}+1\right)
$$

dengan $u(x, t)$ merupakan solusi persamaan, $f(x)$ merupakan suatu fungsi sebarang dari variabel $x$, serta $k$ merupakan suatu konstanta.

\section{DAFTAR PUSTAKA}

Handayani, Maria Ulfah, Zahrani Dalimunthe, and Rika Sari Indah. (2017). Penentuan Aliran Fluida Dengan Menggunakan Persamaan Navier-Stokes Dan Bantuan Persamaan Diferensial. Prosiding (November 2016): 1-5.

Hapsoro, Aji,C., and Srigutomo, W. (2018). Pemodelan Aliran Fluida 2-D Pada Kasus Aliran Permukaan Menggunakan Metode Beda Hingga. Bandung: Institut Teknologi Bandung.

Khudzaifah, M. . (2017). Penyelesaian Persamaan Diferensial Parsial Non Linier Dengan Metode Baru Yang Lebih Efisien. Jurnal Ilmiah \& Edukasi Sosial. 50-58.

Landajuela, M. . (2011). Burgers Equation. Paris: Basque Center for Applied Mathematics.

Mungkasi, S. (2020). Effects of a Logistik Reaction to Finite Difference Numerical Solutions of the Inviscid Burgers Equation. Indonesian Journal of Information Systems, 2(2). 11.

Nagle, R.K., Saff, E.B., \& Snider, A.D.. (2012). Fundamentals of Differential Equation and Boundary Value Problems. New York: Addison Wesley.

Ripai, A., Abdullah, Z., \& Syafwan, M. (2019). Analisis Solusi Persamaan Burger sebagai Solusi Soliton Menggunakan Transformasi Hopf-Cole, 8(2). 171-177.

Salih, A. (2015). Inviscid Burgers' Equation 1 Nonlinear Wave Equation. (February): 1-16.

Side, S. . (2014). Persamaan Diferensial Parsial. Makassar: Diktat 